\title{
Rural and urban views on elephants, conservation and poaching
}

\author{
Christie Sampson, Jenny Anne Glikman, S. L. Rodriguez, David Tonkyn \\ Paing Soe, David O’Connor, Aung Myo Chit and Peter Leimgruber
}

\begin{abstract}
Successful anti-poaching policies and effective conservation of Asian elephants Elephas maximus require input and support from all stakeholders, including the public. But although Myanmar has one of the largest remaining populations of wild Asian elephants, there has been little research on public attitudes there towards elephants and poaching. We developed a questionnaire to assess attitudes of people in rural and urban areas towards elephants and conservation, and their perceptions of and experience with elephant poaching. We conducted 178 interviews across two regions in Myanmar. Although both rural and urban participants supported elephant conservation, people from urban areas expressed more favourable attitudes towards elephants than their rural counterparts. Similarly, conservation priorities differed between rural and urban communities, with rural communities less likely to believe that peaceful human-elephant coexistence was possible and preferring conservation initiatives that prioritize human activities over elephant conservation. Both groups were familiar with elephant poaching in Myanmar, but rural communities appeared to be better informed regarding the challenges faced by conservation agencies, and were more negatively affected by poaching. Our findings highlight potential areas for intervention by government
\end{abstract}

Christie SAMPSON $^{*} \dagger$ (Corresponding author, (DD orcid.org/0000-0003-1873-4355) and S. L. RodrigueZ ${ }^{*}$ (iD orcid.org/0000-0002-2605-4336) Department of Forestry and Environmental Conservation, Clemson University, Clemson, SC 29634, USA. E-mail csampso@g.clemson.edu

Jenny AnNe Glikman‡ (DiD orcid.org/0000-0002-0208-5488) Instituto de Estudios Sociales Avanzados, Córdoba, Spain

DAvid Tonkyn (D orcid.org/0000-0001-9033-5776) Department of Biological Sciences, Clemson University, Clemson, USA

PAING Soe World Wildlife Fund-Myanmar, Yangon, Myanmar

DAVID O'CONNOR\$ (D orcid.org/0000-0001-8604-1812) Institute for Conservation Research San Diego Zoo Global, Escondido, USA

Aung Myo Chit and Peter Leimgruber (D orcid.org/0000-0002-3682-0153) Smithsonian Conservation Biology Institute, National Zoological Park, Front Royal, USA

*Also at: Smithsonian Conservation Biology Institute, National Zoological Park, Front Royal, USA

$\dagger$ Also at: Department of Biological Sciences, Clemson University, Clemson, USA

¥Also at: Institute for Conservation Research, San Diego Zoo Global, Escondido, USA

§Also at: Save Giraffes Now, Dallas, USA

-Also at: The Faculty of Biological Sciences, Goethe University, Frankfurt am Main, Germany

Received 25 February 2020. Revision requested 29 July 2020.

Accepted 29 January 2021. First published online 30 September 2021. and conservation agencies to reduce criminal activity and to protect both Myanmar's citizens and its elephants.

Keywords Asia, attitudes, conservation, Elephas maximus, illegal wildlife trade, perception, poaching, wildlife value orientation

Supplementary material for this article is available at doi.org/10.1017/So030605321000156

\section{Introduction}

Wildlife agencies have documented the negative impacts of poaching on wildlife, but rarely attempted to quantify the threat that the international wildlife trade poses to people (WWF/Dalberg, 2012). Some studies have documented links between the illegal wildlife trade and violence, organized crime and human trafficking (WWF/ Dalberg, 2012; Brashares et al., 2014; Douglas \& Alie, 2014). However, community perceptions of wildlife poaching can vary as a result of factors that include the underlying motivation for poaching (e.g. subsistence, commercial, perceived injustice; Harrison et al., 2015), cultural traditions, economic status, and the relationships between poachers and the communities affected by poaching (McCay, 1984; Kuriyan, 2002; Rippl, 2002; Hampshire et al., 2004). Regardless of these perceptions, poaching poses a risk to both people and wildlife.

Biodiversity is generally richest in rural areas, particularly in developing nations (Myers et al., 2000), and these areas are often poaching hotspots. Rural communities frequently experience poverty and food insecurity, and have more limited access to education and health care compared to their urban counterparts. Wildlife conservation policy and management often affect marginalized rural communities by reducing their access to natural resources, which can lead to negative attitudes towards conservation (Woodroffe et al., 2005; Mwangi et al., 2016) and jeopardize human-wildlife coexistence (Parry \& Campbell, 1992; Woodroffe et al., 2005). In contrast, people living in urban areas are often unaware of the difficulties that rural communities face, including reduced access to resources, intimidation by poachers and threats posed by wildlife. Consequently, urban and rural communities may have opposing experiences with, perceptions of, and attitudes towards poaching, illegal wildlife trade and conflict involving wildlife (Bandara \& Tisdell, 2003). 
Poaching can increase if local communities suffer from negative interactions with wildlife (Mehta \& Kellert, 1998; Kansky \& Knight, 2014) or perceive restrictions imposed by conservation policies as unfair (Harrison et al., 2015). In such circumstances, communities may poach in retaliation against the species that are the focus of such policies (Kissui, 2008; Gore et al., 2013) or as a means to decrease or prevent future conflict involving wildlife (Sánchez-Mercado et al., 2008). In contrast, people living in urban areas rarely experience negative interactions with wildlife, but instead may enjoy the benefits associated with conservation (e.g. improved income from tourism; Holechek \& Valdez, 2018). In addition, urbanites are more likely to hold idealized views of charismatic species such as elephants (Bandara \& Tisdell, 2003), and may not be fully aware of the complexities around poaching, conservation and human-wildlife coexistence.

Attitudes, beliefs and norms drive the way individuals think about and behave towards wildlife (Fulton et al., 1996; Whittaker et al., 2006). Determining the attitudes of local communities towards wildlife can help agencies to create effective conservation strategies that align with stakeholder priorities. Similarly, understanding local norms can inform whether agencies can expect people to abide by wildlife protection laws or engage in poaching activities (St. John et al., 2015).

Myanmar is a critical area for the conservation of the Asian elephant Elephas maximus (Leimgruber et al., 2003), but levels of poaching in the country are high (Sampson et al., 2018). To improve elephant conservation in Myanmar, we sought to: (1) assess attitudes and perceptions of urban and rural communities regarding Myanmar's elephant populations, (2) assess their experience with, attitudes towards and perceptions of poaching activities and products derived from poached elephants, (3) determine their willingness and motivations for complying with elephant conservation laws, and (4) identify the impacts of elephant poaching experienced by community members.

\section{Study area}

To assess the views of people living near elephants in rural areas and those in urban areas without elephants, we interviewed communities across central and western Myanmar during December 2016-May 2018 (Fig. 1). We interviewed people in easily accessible villages in two rural areas: 20 villages in the Ayeyarwady Delta region and 11 villages in the foothills of the southern Bago Yoma mountain range. All urban interviews were conducted in Yangon, the former capital of Myanmar.

\section{Methods}

\section{Questionnaire}

Our questionnaire consisted of 34 items in four sections (Table 1). The first section covered demographical

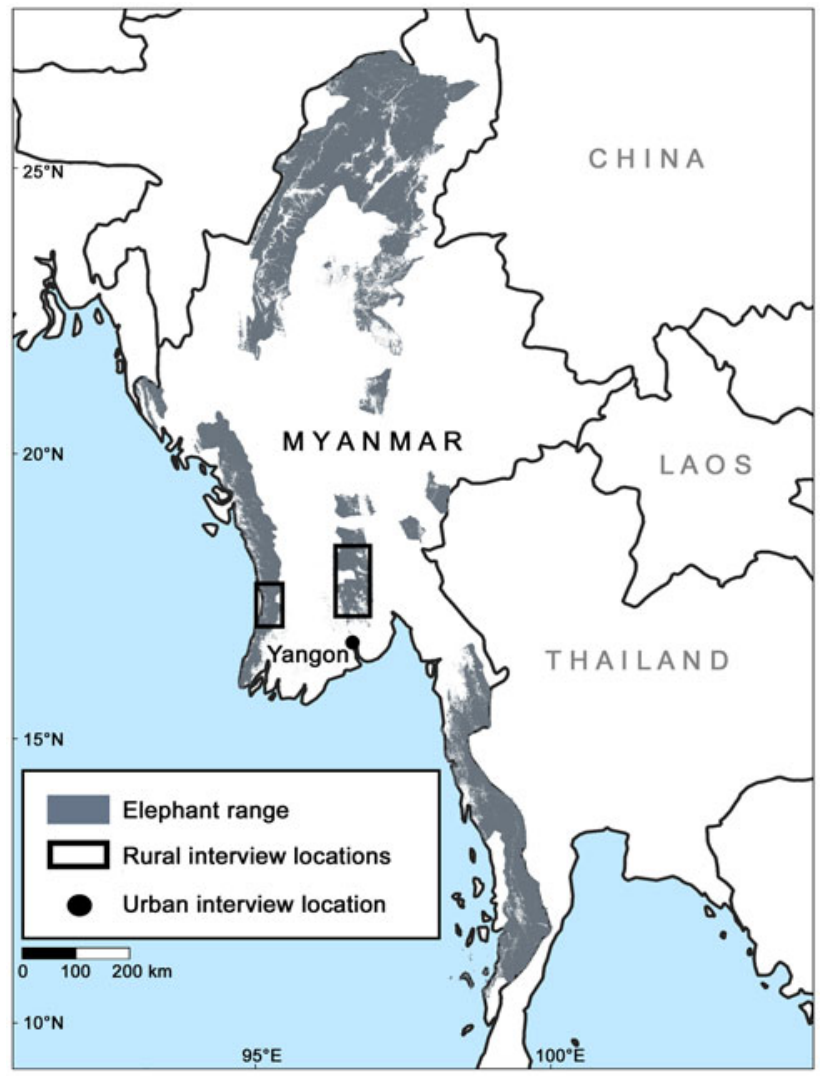

FIG. 1 Locations of interview surveys on elephants and elephant poaching in rural and urban locations in Myanmar (December 2016-May 2018).

characteristics of participants. The second investigated their attitudes towards elephants and perceptions of the costs and benefits of living with them. The third part asked participants about their knowledge of elephants, and their motivation to comply with conservation laws. The final section explored the participants' experiences and perceptions of hunting and poaching. An 'I do not know' response option was provided for all questions and was treated as a non-response in the analyses.

We administered the questionnaire orally in the Myanmar language (Supplementary Material Appendix 1). Interviews lasted c. 30 minutes, and were conducted by CS and 12 field crew members from local conservation organizations and academic institutions who had participated in a training session covering the approved interview protocol and data recording methods.

\section{Participant recruitment}

We used a mixed method approach for recruiting participants. In villages, we implemented a stratified random sampling framework. The interviewer approached the first house they saw to request an interview. If no adults were present in the home, or residents did not wish to participate 
TABLE 1 Summary of the questions included in our study of views and perceptions of elephant poaching in rural and urban communities in Myanmar (December 2016-May 2018).

\begin{tabular}{|c|c|c|c|}
\hline Section & Category & Type $^{1}$ & Question/statement \\
\hline \multirow[t]{4}{*}{$\mathrm{I}$} & \multirow[t]{4}{*}{ Demographics } & MC & Gender \\
\hline & & & Ethnicity \\
\hline & & & Religion \\
\hline & & Open & Age \\
\hline \multirow[t]{12}{*}{ II } & \multirow[t]{6}{*}{ Attitudes towards elephants } & \multirow[t]{6}{*}{ Likert } & Elephants are an important part of Myanmar's culture \\
\hline & & & Elephants are important to the ecosystem \\
\hline & & & Elephants are important to conserve for future generations \\
\hline & & & It is important to protect elephant habitat in Myanmar \\
\hline & & & It is possible to use the same land as elephants \\
\hline & & & Elephants are important for religious reasons \\
\hline & \multirow[t]{6}{*}{$\begin{array}{l}\text { Perceptions of the costs \& benefits } \\
\text { of elephants }\end{array}$} & \multirow[t]{6}{*}{ Likert } & $\begin{array}{l}\text { Elephants should be protected because they bring more benefits to } \\
\text { this community than they do problems }\end{array}$ \\
\hline & & & $\begin{array}{l}\text { Elephants \& livestock compete for water \& grazing, but the needs of } \\
\text { livestock remain more important than the needs of wildlife \& should } \\
\text { always be prioritized }\end{array}$ \\
\hline & & & $\begin{array}{l}\text { The needs of humans should take priority over elephant conservation } \\
\text { efforts }\end{array}$ \\
\hline & & & It is acceptable for elephants to be used in the timber industry \\
\hline & & & It is acceptable for elephants to be used in the tourism industry \\
\hline & & & $\begin{array}{l}\text { Conserving elephants is a waste of resources as it leads to more conflict } \\
\text { within the community }\end{array}$ \\
\hline \multirow[t]{8}{*}{ III } & \multirow[t]{4}{*}{$\begin{array}{l}\text { Knowledge about the conservation } \\
\text { status of elephants in Myanmar }\end{array}$} & $\mathrm{MC}$ & $\begin{array}{l}\text { Over the last } 5 \text { years, what has happened to the elephant population } \\
\text { in Myanmar? }\end{array}$ \\
\hline & & $\mathrm{T} / \mathrm{F}$ & Elephants are legally protected in Myanmar \\
\hline & & & Asian elephants are Endangered \\
\hline & & & $\begin{array}{l}\text { Myanmar has the most expansive remaining elephant habitat out of } \\
\text { all the countries that have Asian elephants }\end{array}$ \\
\hline & \multirow{4}{*}{$\begin{array}{l}\text { Motivations for compliance with } \\
\text { elephant conservation laws }\end{array}$} & \multirow[t]{4}{*}{ Likert } & I know the laws that apply to wildlife in my country \\
\hline & & & $\begin{array}{l}\text { Most of my friends think that we should protect our livestock \& crops } \\
\text { even if that means breaking rules that apply to elephants }\end{array}$ \\
\hline & & & $\begin{array}{l}\text { Most of my friends think that we should comply with laws that apply } \\
\text { to not harming elephants }\end{array}$ \\
\hline & & & $\begin{array}{l}\text { I have a moral obligation to comply with rules concerning elephant } \\
\text { protection }\end{array}$ \\
\hline \multirow[t]{13}{*}{ IV } & \multirow{13}{*}{$\begin{array}{l}\text { Participants' experiences with } \\
\text { \& perception of hunting } \\
\text { \& poaching }\end{array}$} & \multirow[t]{7}{*}{$\mathrm{Y} / \mathrm{N}$} & Have you ever personally seen poached elephant parts? \\
\hline & & & Do you think people that poach animals feel ashamed for doing so? \\
\hline & & & Are you afraid of elephant poachers? \\
\hline & & & Do Myanmar people help poachers from other countries find elephants in \\
\hline & & & Myanmar? \\
\hline & & & Do Myanmar people help poachers avoid capture? \\
\hline & & & Have you ever seen an elephant poacher? \\
\hline & & Likert & $\begin{array}{l}\text { I think those people who break the rules concerning wildlife protection } \\
\text { should be punished }\end{array}$ \\
\hline & & MC & Which parts of a dead elephant are being taken by poachers? \\
\hline & & & In your opinion, which country do elephant poachers come from? \\
\hline & & & How likely are people who kill elephants to get caught? \\
\hline & & Open & Why do people poach elephants? \\
\hline & & & Why are you afraid of poachers? \\
\hline
\end{tabular}

${ }^{1} \mathrm{MC}$, multiple choice; Open, open ended; Likert, 5-point Likert statement, with $1=$ strongly disagree, $3=$ neutral and $5=$ strongly agree; $\mathrm{T} / \mathrm{F}$, true or false; $\mathrm{Y} / \mathrm{N}$, yes or no.

in the study, the interviewer moved on to the nearest house and every subsequent house until they found a willing participant. Once the interviewer had completed a survey, they skipped the nearest two houses and approached the third home for participation. In addition to the household sampling, we employed a convenience sampling approach to recruit participants in communal areas in villages (e.g. tea shop, bus stop). The interviewer approached the first potential 
participant they saw upon arrival at the location. Once the interview was completed, the interviewer allowed three people to pass before approaching the next potential participant.

For the urban sample, we used the convenience sampling approach to recruit participants in Yangon in five public locations: Mingalar market, People's Park, Sule Pagoda, Kandawgyi Park and Sule Park. We also conducted interviews in two nature-themed urban locations, Yangon Zoo and Hlawga National Park. We found no difference in responses between public and nature-themed locations for all but one question (Supplementary Material 2), and therefore combined responses into a single dataset for urban areas.

\section{Data analysis}

We determined data distribution to be non-normal, using the Shapiro-Wilk test (Shapiro \& Wilk, 1965). We used the nonparametric unpaired two-sample Wilcoxon rank-sum test (Hollander et al., 1973) to test for significant ( $\alpha=0.05$ ) differences of the Likert scale responses between participants from urban and rural locations. We used $\chi^{2}$ tests to test for significance $(\alpha=0.05)$ for all other question types. We determined effect size using Cohen's $d$ (Cohen, 1988). Statistical analyses were conducted in $R$ 3.5.1 (R Core Team, 2013).

\section{Results}

We conducted a total of 178 interviews, 83 in rural and 95 in urban locations. The mean age was was $41 \pm$ SE 1.5 and $28 \pm$ SE 1 years old for rural and urban participants, respectively. Rural interviewees were primarily men (67 men, 15 women), whereas the numbers of men and women in the urban sample were nearly equal (46 and 44, respectively). Gender was not reported for one rural participant and five urban participants. The majority of the participants selfidentified as Burmese in both rural (71\%) and urban (69\%) locations, and the remaining participants as Rakhine, Mon, Kayin, Chin or other. Most participants were Buddhist (92\% rural and 88\% urban, respectively), with the remainder following Christian, Hindu, Muslim or other religions.

\section{Attitudes towards elephants}

Overall, both rural and urban participants had positive attitudes towards elephants. Both groups displayed a similar level of belief that elephants should be protected because of the benefits they provide to people (Supplementary Material 3). Enjoyment from seeing elephants was the benefit most reported by rural participants $(81 \%, n=78)$, followed by job creation in the tourism and conservation industries. Urban participants reported that income from tourists coming to Myanmar to see elephants was the most common benefit they received $(77 \%, n=74)$, followed by the labour elephants provide $(73 \%, \mathrm{n}=70)$.

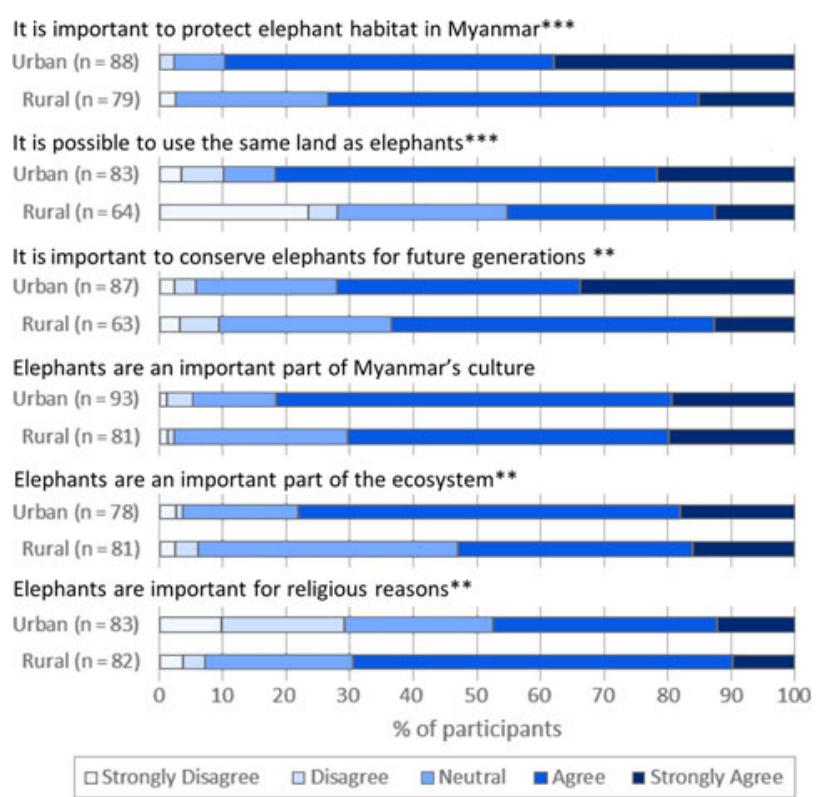

FIg. 2 Attitudes of rural and urban participants in Myanmar towards elephants on a 5-point Likert scale (December 2016May 2018). Asterisks denote significant differences between urban and rural respondents: ${ }^{* *} \mathrm{P}<0.01,{ }^{* *} \mathrm{P}<0.001$.

Rural participants were significantly more likely to agree that elephants were an important part of religion in Myanmar ( $\mathrm{P}<0.01$; Fig. 2), but less likely to believe it is possible to coexist with them ( $\mathrm{P}<0.001$; Fig. 2$)$. Rural participants were also less likely to believe it is possible to share the same land with elephants $(\mathrm{P}<0.001$; Fig. 2$)$ or that it is acceptable for elephants to be used in the tourism $(\mathrm{P}<0.01$; Fig. 3) and timber industries $(\mathrm{P}<0.001$; Fig. 3). Rural respondents were more likely to prioritize the needs of humans over the needs of the wild elephant population than urban participants ( $\mathrm{P}<0.001$; Fig. 3).

\section{Knowledge about elephants and conservation}

We found no significant difference between rural and urban participants in knowledge about the conservation status of Asian elephants in Myanmar. The majority of both rural $(97 \% ; \mathrm{n}=79)$ and urban $(89 \% ; \mathrm{n}=73)$ participants correctly identified that elephants were an Endangered species that was legally protected, and that out of all countries with Asian elephants Myanmar had the largest extent of remaining elephant habitat (rural $=90 \%, n=58$; urban $=81 \%, n=64$; Supplementary Material 4 ). When asked about their perceptions of changes to the status of Myanmar's elephant population over the past 5 years, $58 \%(n=83)$ of rural and $38 \%(n=95)$ of urban participants believed the elephant population had decreased. Both groups pointed to poaching as the greatest threat to wild elephants (rural $=67 \%, \mathrm{n}=79$; urban $=57 \%$, $\mathrm{n}=81$; Supplementary Material 5), followed by habitat degradation (rural $=24 \%, \mathrm{n}=79$; urban $=37 \%, \mathrm{n}=81$ ). 
It is acceptable for elephants to be used in the timber industry*** Urban $(n=89)$

Rural $(n=82)$

It is acceptable for elephants to be used in the tourism industry**

Urban $(\mathrm{n}=90)$

Rural ( $\mathrm{n}=82)$

Elephants should be protected because they bring more

benefits than problems to this community

Urban $(n=80)$

Rural $(\mathrm{n}=79)$

The needs of humans should take priority over elephant conservation efforts*** Urban $(n=80)$

Rural $(n=79)$

The needs of livestock remain more important than the needs of wildlife and should always be prioritized $* * *$

Urban $(n=81)$

Rural $(n=79)$

Conserving elephants is a waste of resources as it

leads to more conflict within the community **

Urban $(n=71)$

Rural ( $n=75$ )

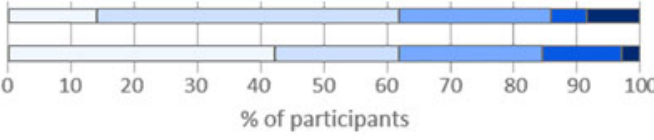

aStrongly Disagree $\square$ Disagree neutral a Agree =Strongly Agree

FIg. 3 Perceptions of rural and urban participants in Myanmar of the costs and benefits of living with elephants on a 5-point Likert scale (December 2016-May 2018). Asterisks denote significant differences between urban and rural respondents: ${ }^{* *} \mathrm{P}<0.01,{ }^{* * *} \mathrm{P}<0.001$.

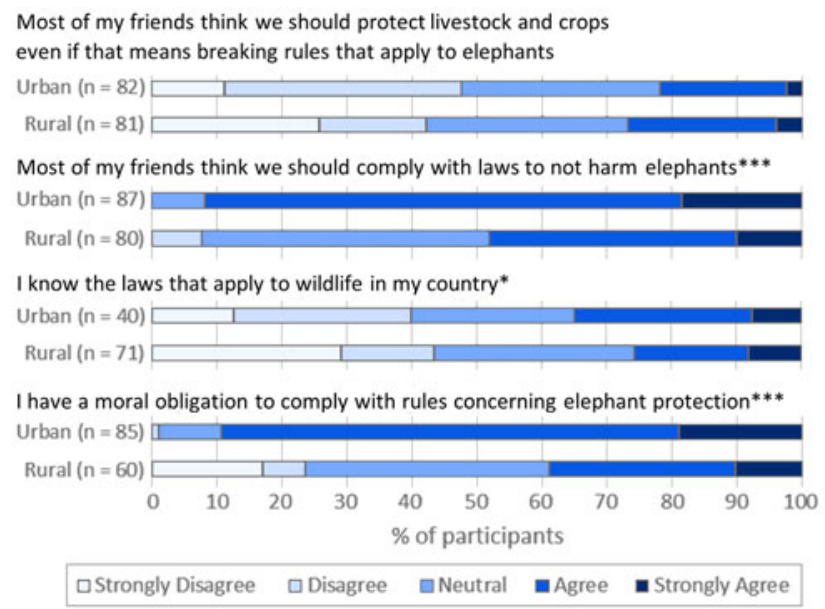

Fig. 4 Motivations of rural and urban participants in Myanmar to comply with wildlife laws (December 2016-May 2018). Asterisks denote significant differences between urban and rural respondents: ${ }^{\star} \mathrm{P}<0.05,{ }^{\star * \star} \mathrm{P}<0.001$.

Urban participants were significantly more likely than rural participants to state they were familiar with the country's wildlife laws $(\mathrm{P}=0.03$; Fig. 4$)$ and believed they had a moral obligation to comply with elephant protection regulations $(\mathrm{P}<0.001$; Fig. 4). Both groups showed strong motivation for complying with laws that protect elephants (Fig. 4). Seventy per cent of rural $(n=80)$ and $92 \%$ of urban $(\mathrm{n}=87)$ participants agreed that wildlife poachers should be punished for their actions, and $>90 \%$ of both rural and urban participants believed that elephant poachers are likely to be captured by authorities.

Most rural $(70 \%, \mathrm{n}=79)$ and fewer urban $(28 \%, \mathrm{n}=78)$ participants reported being afraid of poachers (Table 2), for reasons including that poachers are 'bad' and 'aggressive', 'bring guns and violence', and 'they can kill me'. Most rural participants $(76 \%, \mathrm{n}=26)$ indicated that elephant poachers were native to Myanmar, whereas most urban participants $(85 \%, \mathrm{n}=53)$ assumed that poachers came from both Myanmar and other countries. Both groups thought that the primary reason for poaching was for monetary gain $(n=58)$. When asked which parts of the elephant were taken by poachers, rural participants most commonly indicated tusks $(64 \%, \mathrm{n}=83$; Supplementary Material 6) and skin $(39 \%)$, whereas urban participants mentioned tusks $(69 \%, \mathrm{n}=95)$, skin $(18 \%)$, or stated they did not know or did not answer the question (18\%).

\section{Discussion}

\section{Attitudes towards elephants}

Although both groups of participants overall had a positive view of elephants, there was a distinction in rural and urban attitudes towards elephants. Rural communities commonly see elephants as pests (De Boer \& Baquete, 1998; Tisdell \& Xiang, 1998), which may explain why rural participants rejected the possibility of human-elephant coexistence and were less supportive of protecting elephant habitat. Similarly, the threat of negative interactions with elephants may lead rural communities to deny the species' ecological importance and undermine their support for elephant conservation. However, rural residents perceived that elephants had a significantly greater importance in religion than did urban residents, although a majority of all participants self-identified as Buddhists.

\section{Costs and benefits of living with elephants}

Effective elephant conservation may result in increased wild populations and consequently greater challenges with respect to coexistence with people. Despite this, both urban and rural respondents felt that conserving elephants was not a waste of resources. Elephants can cause significant damage to crops and sometimes livestock (Fernando et al., 2005; Rodriguez \& Sampson, 2019), which affects rural communities more directly than people in urban areas. Increasing negative interactions as a result of conservation actions (Redpath et al., 2013) could result in rural participants being more inclined to prioritize the needs of people and livestock over elephant conservation. However, our findings 
TABLE 2 Summary statistics of yes/no responses and number of rural and urban participants who responded to the questions about their experiences with poaching in Myanmar (December 2016-May 2018).

\begin{tabular}{lllr}
\hline Question & Rural \% Affirmative (n) & Urban \% Affirmative (n) & P \\
\hline Are you afraid of elephant poachers? & $70 \%(79)$ & $28 \%(78)$ & $<0.0001$ \\
Do Myanmar people help poachers from other & $55 \%(73)$ & $56 \%(85)$ & 77.990 \\
$\quad$ countries find elephants in Myanmar? & & & 0.9254 \\
Do Myanmar people help poachers avoid capture? & $39 \%(75)$ & $42 \%(71)$ & 0.009 \\
Have you ever seen an elephant poacher? & $59 \%(76)$ & $6 \%(85)$ & 0.659 \\
\hline
\end{tabular}

suggest that elephants could also provide benefits to rural communities through the enjoyment people receive from seeing elephants, as reported by Gadd (2005), and through mechanisms such as job creation in ecotourism and providing labour in the transportation and timber industries.

\section{Knowledge of and views on elephant conservation}

The most recent assessment of the Asian elephant population in Myanmar was published in 2004 (Leimgruber \& Wemmer, 2004). Despite the commitment and efforts of conservation agencies and the government of Myanmar to conserve the country's remaining 1,430-2,065 wild elephants (Leimgruber \& Wemmer, 2004), recent research (Sampson et al., 2018) suggests that poaching may be occurring at a higher rate than previously suggested. Local knowledge can be valuable in determining trends in wildlife populations (e.g. Mallory et al., 2003; Gilchrist et al., 2005), and could provide insights on elephant population numbers and distribution (Songer et al., 2016). That a majority of rural participants believed the elephant population is decreasing may suggest that the estimate from 2004 is now outdated.

Both rural and urban participants stated that poaching is the greatest threat to wild elephant populations. Sampson et al. (2018) reported that elephant populations in the rural areas where we conducted interviews had been targeted by poachers in the months immediately prior to our study. In addition, surveys conducted in Myanmar's legal wildlife markets have shown a $400 \%$ increase in elephant skin available for purchase during 2009-2014, suggesting a rise in consumer demand (Underwood et al., 2013; Nijman \& Shepherd, 2014).

Some of the participants' responses were contradictory. For example, rural respondents supported protecting elephant habitat although they were less likely than urban participants to agree that habitat destruction and agricultural expansion were threats to elephants. This probably reflects the dependence of rural populations on farming and a reluctance to admit that these activities can be detrimental to elephants. Habitat loss is a major concern for wildlife conservation in Myanmar (Bhagwat et al., 2017) and for Asian elephants throughout their range (Leimgruber et al., 2003, 2008; Songer et al., 2016). Most respondents were aware that Myanmar has the largest expanse of continuous elephant habitat within the species' range (Leimgruber et al., 2003), a fact that conservation agencies could use in communicating the importance of regulating development of wild areas to maintain this unique and important resource.

\section{Motivations for compliance with conservation laws}

Myanmar's wildlife protection laws prohibit the killing of elephants and the possession of any elephant body part, with punishments of up to 10 years in prison (State Law and Order Restoration Council Law No.583/94.1994). Given that most participants believed that wildlife authorities would be likely to capture elephant poachers, it is unsurprising that both rural and urban participants indicated they are compliant with wildlife laws. However, as many participants indicated they were not fully aware of the wildlife laws in Myanmar, there is an opportunity for conservation agencies to invest in community education and engagement to ensure wildlife laws are better understood by citizens in both rural and urban areas.

\section{Experiences with and perception of hunting and poaching}

The drivers behind poaching can be complex. Some people poach wildlife for subsistence, others for commercial reasons or elevation of social status (Eliason, 1999). Many participants believed that poachers killed elephants for money. In Myanmar, the mean income of farmers is c. USD 1,000 per year (C. Sampson, unpubl. data). In contrast, people can be paid up to USD 4,0oo for assisting a poacher to find an elephant (Z. M. Oo, pers. comm., 2017), and dried elephant skin is sold for up to USD 3.65 per square inch (Hla Hla Htay \& Henshaw, 2017). This provides considerable financial motivation for poaching or assisting poachers. Rural participants listed a greater variety of elephant body parts taken by poachers, aligning with reports from the Myanmar government, which suggests rural participants are more familiar with the wildlife trade.

Respondents in our study described observing violent behaviour by poachers and indicated they fear them, findings that are corroborated by reports that citizens are afraid to 
alert authorities to poaching activities for fear of retaliation (Kyaw Ko Ko, 2018). Elephants and other wildlife are highvalue natural resources (Douglas \& Alie, 2014), and the number of elephants poached appears to be increasing annually (Sampson et al., 2018). Local communities and the Myanmar government may need to protect citizens as populations of high-value species decline, as the activities of criminal organizations can result in social unrest and violence.

\section{Implications for conservation}

Understanding the attitudes and belief systems underlying citizens' support for elephant conservation can help guide the creation of effective conservation strategies that integrate traditional values and modern science. Our interview survey indicates that the people of Myanmar recognize the importance of mitigating the expansion of human activities into wild areas, to protect elephants. This suggests they are probably willing to support conservation initiatives to protect elephant habitat. Similarly, highlighting the role of elephants in Myanmar's culture and their religious importance can encourage rural communities to adopt behaviours that benefit elephants.

Communities do not appear to be actively engaging in conservation activities to reduce poaching, despite their stated support for elephant protection and willingness to comply with relevant laws. Conversations with community leaders and local wildlife authorities suggest that actions such as assisting poachers may be financially motivated and driven by low levels of income and the high rewards paid by poachers. Given the deeply religious nature of many people in Myanmar and the Buddhist tenet that prohibits the killing of any living creature, developing and implementing programmes in collaboration with religious authorities to stigmatize working with poachers may help to counteract any financial incentives for doing so.

Our findings suggest that the government and associated elephant conservation agencies need to expand their mitigation efforts to include addressing the consequences of poaching and the illegal wildlife trade felt by human populations in Myanmar (e.g. elevated levels of fear and perceived potential for violence). Growing demand for elephant products (Sampson et al., 2018) may lead to further declines in the elephant population and greater efforts from poachers to locate them, potentially increasing perceived violence against communities. Other studies of declines of high-value wildlife have shown that, as more effort is needed to locate the animals, there can be an increase in organized crime and the forced conscription of children and adults into the illegal wildlife trade (WWF/Dalberg, 2012; Brashares et al., 2014).

Future studies should assess the part that local communities play in poaching (e.g. not reporting poachers, assisting them to locate elephants and transfer poached products) and their motivation for doing so. This information would help conservation organizations develop strategies to overcome any barriers to comply with anti-poaching laws. Additional studies that examine the structure of poaching operations, which is challenging given their illicit nature, could assist law enforcement in identifying and disrupting poaching activities. In addition, identifying vulnerable communities and community members may facilitate the development of educational outreach and intervention programmes, to prevent poachers from engaging them in activities that are both illicit and destructive to their own natural resources and livelihood security.

Acknowledgements We thank the community members in Myanmar for their participation; U Khin Maung Gyi, U Myint Aung, Daw Khine Khine Swe and Aung Nyein Chan for their input and guidance in conducting the research; Zin Hline Htun, Nyi Win Kyaw Kyaw, Dr. Idd Idd Shwe Zin, Chan Nyein Aung, Zayar Soe, Ne Eindray Khin, Padang Aung, Bo Kyaw Htwe, La Pyae Wun, Kuang Thet Kyaw Zawe, Yan Lin Tun, Margaret Nyein Nyein Myint and Shane Thiha Soe for their assistance with fieldwork; and Christy Williams, Nicholas Cox and the staff of WWF-Myanmar for their support. Permission for this study was granted by the Myanmar Ministry of Natural Resources and Environmental Conservation. This study was funded by the U.S. Fish \& Wildlife Service Asian Elephant Conservation Fund (\#ASE1648).

Author contributions Study design: CS, JAG; fieldwork: CS, PS; data analysis: CS, JAG, SLR, PL; writing: CS, JAG, SLR, DT; revision: all authors.

\section{Conflicts of interest None.}

Ethical standards This research abided by the Oryx guidelines on ethical standards and was conducted with permission under the Memorandum of Understanding between the Myanmar Government and the Smithsonian Conservation Biology Institute. The questionnaire and study design were approved by the institutional review boards at Clemson University and the Smithsonian Institution (IRB Protocols \#2014-187 and \#HS17014, respectively), and we obtained prior, informed consent from the interviewees.

\section{References}

Bandara, R. \& Tisdell, C. (2003) Comparison of rural and urban attitudes to the conservation of Asian elephants in Sri Lanka: empirical evidence. Biological Conservation, 110, 327-342.

Bhagwat, T., Hess, A., Horning, N., Khaing, T., Thein, Z.M., AUnG, K.M. et al. (2017) Losing a jewel - rapid declines in Myanmar's intact forests from 2002-2014. PLOS ONE, 12, e0176364.

Brashares, J.S., Abrahms, B., Fiorella, K.J., Golden, C.D., Hojnowski, C.E., MARsh, R.A. et al. (2014) Wildlife decline and social conflict. Science, 345, 376-378.

Cohen, J. (1988) Statistical Power Analysis for the Behavioral Sciences. 2nd edition. Lawrence Earlbaum Associates, Hillsdale, USA.

De Boer, W.F. \& Baquete, D.S. (1998) Natural resource use, crop damage and attitudes of rural people in the vicinity of the Maputo Elephant Reserve, Mozambique. Environmental Conservation, 25, 208-218.

Douglas, L.R. \& Alie, K. (2014) High-value natural resources: linking wildlife conservation to international conflict, insecurity, and development concerns. Biological Conservation, 171, 270-277.

Eliason, S.L. (1999) The illegal taking of wildlife: toward a theoretical understanding of poaching. Human Dimensions of Wildlife, 4, 27-39. 
Fernando, P., Wikramanayake, E., Weerakoon, D., Jayasinghe, L.K.A., Gunawardene, M. \& Janaka, H.K. (2005) Perceptions and patterns of human-elephant conflict in old and new settlements in Sri Lanka: insights for mitigation and management. Biodiversity and Conservation, 14, 2465-2481.

Fulton, D.C., Manfredo, M.J. \& Lipscomb, J. (1996) Wildlife value orientations: a conceptual and measurement approach. Human Dimensions of Wildlife, 1, 24-47.

GADD, M.E. (2005) Conservation outside of parks: attitudes of local people in Laikipia, Kenya. Environmental Conservation, $32,50-63$.

Gilchrist, G., Mallory, M. \& Merkel, F. (2005) Can local ecological knowledge contribute to wildlife management? Case studies of migratory birds. Ecology and Society, 10, 12.

Gore, M.L., Ratsimbazafy, J. \& Lute, M.L. (2013) Rethinking corruption in conservation crime: insights from Madagascar. Conservation Letters, 6, 430-438.

Hampshire, K., Bell, S., Wallace, G. \& Stepukonis, F. (2004) "Real" poachers and predators: shades of meaning in local understandings of threats to fisheries. Society \& Natural Resources, $17,305-318$.

Harrison, M., Roe, D., Baker, J., Travers, H., Plumptre, A. \& Rwetsiba, A. (2015) Wildlife Crime: A Review of the Evidence on Drivers and Impacts in Uganda. International Institute for Environment and Development, London, UK.

Hla Hla Htay \& Henshaw, C. (2017) The skincare fad threatening Myanmar's elephants. The Myanmar Times, 24 January 2017. $\mathrm{mmtimes.com/national-news/24665-the-skincare-fad-threatening-}$ myanmar-s-elephants.html [accessed July 2021].

Holecheк, J. \& Valdez, R. (2018) Wildlife conservation on the rangelands of Eastern and Southern Africa: past, present, and future. Rangeland Ecology \& Management, 71, 245-258.

Hollander, M., Wolfe, D.A. \& Chicken, E. (1973) Nonparametric Statistical Methods. John Wiley \& Sons, New York, USA.

KANSKY, R. \& KNIGHT, A.T. (2014) Key factors driving attitudes towards large mammals in conflict with humans. Biological Conservation, 179, 93-105.

Kissui, B. (2008) Livestock predation by lions, leopards, spotted hyenas, and their vulnerability to retaliatory killing in the Maasai steppe, Tanzania. Animal Conservation, 11, 422-432.

KURIYAN, R. (2002) Linking local perceptions of elephants and conservation: Samburu pastoralists in northern Kenya. Society \& Natural Resources, 15, 949-957.

Kyaw Ko Ko (2018) Poachers feed China trade, threaten country's elephants. The Myanmar Times, 19 June 2018. mmtimes.com/news/ poachers-feed-china-trade-threaten-countrys-elephants.html [accessed July 2021].

Leimgruber, P., Gagnon, J.B., Wemmer, C., Kelly, D.S., Songer, M.A. \& SELIG, E.R. (2003) Fragmentation of Asia's remaining wildlands: implications for Asian elephant conservation. Animal Conservation, 6, 347-359.

Leimgruber, P., Senior, B., Aung, M., Songer, M.A., Mueller, T., Wemmer, C. \& Ballou, J.D. (2008) Modeling population viability of captive elephants in Myanmar (Burma): implications for wild populations. Animal Conservation, 11, 198-205.

Leimgruber, P. \& Wemmer, C. (2004) National Elephant Symposium and Workshop. Report to the U.S. Fish \& Wildlife Service and the Myanmar Forest Department, Front Royal, USA.

Mallory, M.L., Gilchrist, H.G., Fontaine, A.J. \& Akearok, J.A. (2003) Local ecological knowledge of ivory gull declines in Arctic Canada. Arctic, 56, 293-298.
McCAY, B.J. (1984) The pirates of Piscary: ethnohistory of illegal fishing in New Jersey. Ethnohistory, 31, 17-37.

Mehta, J.N. \& Kellert, S.R. (1998) Local attitudes toward community-based conservation policy and programmes in Nepal: a case study in the Makalu-Barun Conservation Area.

Environmental Conservation, 25, 320-333.

Mwangi, D.K., Akinyi, M., Maloba, F., Ngotho, M., Kagira, J., Ndeereh, D. \& Kivai, S. (2016) Socioeconomic and health implications of human-wildlife interactions in Nthongoni, Eastern Kenya. African Journal of Wildlife Research, 46, 87-102.

Myers, N., Mittermeier, R.A., Mittermeier, C.G., da Fonseca, G.A.B. \& KENT, J. (2000) Biodiversity hotspots for conservation priorities. Nature, 403, 853-858.

Nijman, V. \& Shepherd, C.R. (2014) Emergence of Mong La on the Myanmar-China border as a global hub for the international trade in ivory and elephant parts. Biological Conservation, 179, 17-22.

Parry, D. \& CAmpbell, B. (1992) Attitudes of rural communities to animal wildlife and its utilization in Chobe Enclave and Mababe Depression, Botswana. Environmental Conservation, 19, 245-252.

R Core Team (2013) R: A Language and Environment for Statistical Computing. R Foundation for Statistical Computing, Vienna, Austria. r-project.org [accessed 14 June 2021].

Redpath, S.M., Young, J., Evely, A., Adams, W.M., Sutherland, W.J. et al. (2013) Understanding and managing conservation conflicts. Trends in Ecology \& Evolution, 28, 100-109.

Rippl, S. (2002) Cultural theory and risk perception: a proposal for a better measurement. Journal of Risk Research, 5, 147-165.

Rodriguez, S.L. \& SAMPSON, C. (2019) Expanding beyond carnivores to improve livestock protection and conservation. PLOS Biology, $17, \mathrm{e} 3000386$.

Sampson, C., McEvoy, J., Oo, Z.M., Chit, A.M., Chan, A.N., Tonkyn, D. et al. (2018) New elephant crisis in Asia - early warning signs from Myanmar. PLOS ONE, 13, eo194113.

Sánchez-Mercado, A., Ferrer-Paris, J.R., Yerena, E., García-Rangel, S. \& Rodríguez-Clark, K.M. (2008) Factors affecting poaching risk to vulnerable Andean bears Tremarctos ornatus in the Cordillera de Merida, Venezuela: space, parks and people. Oryx, 42, 437-447.

Shapiro, S.S. \& Wilk, M.B. (1965) An analysis of variance test for Normality (complete samples). Biometrika, 52, 591.

Songer, M., Aung, M., Allendorf, T.D., Calabrese, J.M. \& Leimgruber, P. (2016) Drivers of change in Myanmar's wild elephant distribution. Tropical Conservation Science, 9, 4.

St. John, F.A.V., MaI, C.H. \& PeI, K.J.C. (2015) Evaluating deterrents of illegal behaviour in conservation: carnivore killing in rural Taiwan. Biological Conservation, 189, 86-94.

Tisdell, C.A. \& Xiang, Z. (1998) Protected areas, agricultural pests and economic damage: conflicts with elephants and pests in Yunnan. The Environmentalist, 18, 109-118.

Underwood, F.M., Burn, R.W. \& Milliken, T. (2013) Dissecting the illegal ivory trade: an analysis of ivory seizures data. PLOS ONE, 8, e76539.

Whittaker, D., VAske, J.J. \& MANFredo, M.J. (2006) Specificity and the cognitive hierarchy: value orientations and the acceptability of urban wildlife management actions. Society \& Natural Resources, $19,515-530$.

Woodroffe, R., Thirgood, S. \& Rabinowitz, A. (eds) (2005) People and Wildlife. Cambridge University Press, Cambridge, UK. WWF/Dalberg (2012) Fighting Illicit Wildlife Trafficking: A Consultation with Governments. WWF, Gland, Switzerland. 